\title{
Inhibition of Neuropathic Pain by Selective Ablation of Brainstem Medullary Cells Expressing the $\mu$-Opioid Receptor
}

\author{
Frank Porreca, ${ }^{1}$ Shannon E. Burgess, ${ }^{1}$ Luis R. Gardell, ${ }^{1}$ Todd W. Vanderah, ${ }^{1}$ T. Philip Malan Jr, ${ }^{1}$ \\ Michael H. Ossipov, ${ }^{1}$ Douglas A. Lappi, ${ }^{2}$ and Josephine Lai ${ }^{1}$ \\ ${ }^{1}$ Departments of Pharmacology and Anesthesiology, University of Arizona, Tucson, Arizona 85724, and ${ }^{2}$ Advanced \\ Targeting Systems, San Diego, California 92121
}

Neurons in the rostroventromedial medulla (RVM) project to spinal loci where the neurons inhibit or facilitate pain transmission. Abnormal activity of facilitatory processes may thus represent a mechanism of chronic pain. This possibility and the phenotype of RVM cells that might underlie experimental neuropathic pain were investigated. Cells expressing $\mu$-opioid receptors were targeted with a single microinjection of saporin conjugated to the $\mu$-opioid agonist dermorphin; unconjugated saporin and dermorphin were used as controls. RVM dermorphin-saporin, but not dermorphin or saporin, significantly decreased cells expressing $\mu$-opioid receptor transcript. RVM dermorphin, saporin, or dermorphin-saporin did not change baseline hindpaw sensitivity to non-noxious or noxious stimuli. Spinal nerve ligation (SNL) injury in rats pretreated with RVM dermorphin-saporin failed to elicit the expected increase in sensitivity to non-noxious mechanical or noxious thermal stimuli applied to the paw. RVM dermorphin or saporin did not alter
SNL-induced experimental pain, and no pretreatment affected the responses of sham-operated groups. This protective effect of dermorphin-saporin against SNL-induced pain was blocked by $\beta$-funaltrexamine, a selective $\mu$-opioid receptor antagonist, indicating specific interaction of dermorphin-saporin with the $\mu$-opioid receptor. RVM microinjection of dermorphin-saporin, but not of dermorphin or saporin, in animals previously undergoing SNL showed a time-related reversal of the SNL-induced experimental pain to preinjury baseline levels. Thus, loss of RVM $\mu$ receptor-expressing cells both prevents and reverses experimental neuropathic pain. The data support the hypothesis that inappropriate tonic-descending facilitation may underlie some chronic pain states and offer new possibilities for the design of therapeutic strategies.

Key words: neuropathic pain; descending facilitation; RVM; $\mu$-opioid receptors; saporin; ON cells
The presence of endogenous pain-modulating mechanisms is well established. Although pain inhibitory systems projecting from the brainstem to the spinal cord offer obvious survival advantages, the role of descending projections that facilitate pain transmission is less clear (Watkins and Mayer, 1982; Wiertelak et al., 1992; Mason et al., 1999). Nevertheless, the presence of pain facilitation mechanisms raises the possibility that their abnormal sustained activity may underlie chronic pain.

Injury to nerves may elicit neuropathic pain characterized, in part, by increased sensitivity to normally non-noxious and noxious stimuli (allodynia and hyperalgesia, respectively) (Payne, 1986; Chaplan and Sorkin, 1997). Aspects of this human condition have been modeled by injury to spinal nerves in animals (Bennett and Xie, 1988; Seltzer et al., 1990; Kim and Chung, 1992; Kim et al., 1997). Increased spontaneous and persistent afferent discharge may be critical in eliciting hypersensitivity of spinal neurons (i.e., central sensitization) (Kirk, 1974; Wall and Gutnick, 1974; Devor, 1991, 1994; Kajander et al., 1992). Both injured as well as adjacent uninjured fibers become spontaneously active after injury (Li et al., 2000; Wu et al., 2001). Manipulations designed to interfere with ascending, large-fiber projections to brainstem nuclei, including spinal transection, ipsilateral and con-

Received March 15, 2001; revised April 26, 2001; accepted May 1, 2001.

We thank Dr. Naomi Rance for access to the image-assisted mapping equipment and software as well as for her critical evaluation of the in situ hybridization data.

Correspondence should be addressed to Dr. Frank Porreca, Department of Pharmacology, College of Medicine, University of Arizona Health Sciences Center, Tucson, AZ 85724. E-mail: frankp@u.arizona.edu.

Copyright (C) 2001 Society for Neuroscience 0270-6474/01/215281-08\$15.00/0 tralateral hemisections, and selective lesions of the ipsilateral or contralateral (relative to the side of peripheral nerve injury) dorsal columns block nerve injury-induced pain (Bian et al., 1998; Sung et al., 1998; Sun et al., 2001). Lidocaine injection into the ipsilateral (relative to the side of peripheral nerve injury), but not contralateral, nucleus gracilis also blocks nerve injury-induced pain (Sun et al., 2001). These studies support a role for central processes in the mediation of experimental neuropathic pain.

Blockade of established nerve injury-induced pain is also produced by lidocaine microinjection into the rostral ventromedial medulla (RVM), indicating additionally the importance of descending modulatory pathways (Pertovaara et al., 1996; Kovelowski et al., 2000) and the possibility of tonic discharge of cells mediating descending facilitation (Fields et al., 1991; Fields, 1992). The importance of descending facilitation is also supported by observations that lesions of the dorsolateral funiculus (DLF) block nerve injury-induced pain (Ossipov et al., 2000). One characteristic of RVM cells that may mediate descending facilitation is their sensitivity to opioid $\mu$ receptor agonists (Fields et al., 1983; Fields and Heinricher, 1989; Pan et al., 1990; Heinricher et al., 1994). These findings suggest that RVM cells that may mediate descending facilitation in chronic pain states might be identified by their expression of this opioid receptor.

The present experiments tested this hypothesis by targeting RVM $\mu$ receptor-expressing cells with the cytotoxin saporin, by conjugating the toxin to a potent opioid $\mu$ receptor agonist, dermorphin (Broccardo et al., 1981; Braga et al., 1984). The goal was to determine the role of RVM $\mu$-opioid receptor-expressing 
cells in preventing or reversing nerve injury-induced pain. A similar approach has been successfully used to lesion spinal cord lamina I projection cells with a substance $\mathrm{P}$-saporin conjugate (Mantyh et al., 1997; Nichols et al., 1999).

\section{MATERIALS AND METHODS}

Radioligand binding. Radioligand binding was performed using crude membrane preparations from NG 108-15 (expresses mouse opioid $\delta$ receptors) and from transfected cells that express the rat opioid $\mu$ receptors (MORs). All radioligand binding assays were performed in

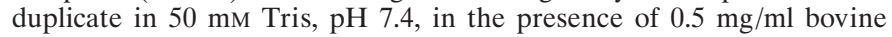
serum albumin (BSA) and protease inhibitors (30 $\mu \mathrm{M}$ bestatin, $10 \mu \mathrm{M}$ captopril, $0.37 \mathrm{U} / \mathrm{ml}$ bacitracin, and $0.1 \mathrm{~mm}$ phenylmethylsulfonyl fluoride). All reactions were performed at $25^{\circ} \mathrm{C}$ for $3 \mathrm{hr}$ in a total reaction volume of $1 \mathrm{ml}$. At least 10 concentrations of dermorphin $\left(10^{-14}\right.$ to $10^{-5}$ $\mathrm{M})$ or dermorphin-saporin $\left(10^{-14}\right.$ to $\left.10^{-7.5} \mathrm{M}\right)$ were used. The concentration of ${ }^{3} \mathrm{H}-\left[\mathrm{D}-\mathrm{Ala}^{2}\right.$, NMPhe ${ }^{4}$, Gly- $\left.01^{5}\right]$ enkephalin $(2.2 \mathrm{nM})$ was based on the $K_{\mathrm{d}}$ value of the radioligand determined from saturation analysis. The reaction was terminated by rapid filtration through Whatman GF/B filters presoaked in polyethyleneimine and washed three times with $4 \mathrm{ml}$ of ice-cold PBS. Nonspecific binding was defined as that in the presence of $10 \mu \mathrm{M}$ naloxone. Radioactivity in the samples was determined by liquid scintillation counting. Data were analyzed by nonlinear regression analysis using GraphPad Prism (Graph Pad, San Diego, CA). The $K_{\mathrm{i}}$ value(s) for each ligand was calculated from the $\mathrm{IC}_{50}$ value(s) based on the Cheng and Prusoff equation from at least three independent experiments.

Intracranial drug microinjection. All rats were prepared for bilateral RVM drug administration as we have described previously (Kovelowski et al., 2000). Anesthetized (ketamine or xylazine, $100 \mathrm{mg} / \mathrm{kg}$, i.p.) animals were placed in a stereotaxic head holder. For intracranial bilateral drug administrations, the skull was exposed, and two 26 ga guide cannulas separated by $1.2 \mathrm{~mm}$ (Plastics One Inc., Roanoke, VA) were directed toward the lateral portions of the RVM (anteroposterior, -2.0 $\mathrm{mm}$; dorsoventral, $0 \mathrm{~mm}$; and lateral, $\pm 0.6 \mathrm{~mm}$ from stereotaxic zero based on the intra-aural line). The guide cannulas were secured to the skull, and the animals were allowed to recover for $5 \mathrm{~d}$ after surgery before any drug administration. Drug administrations into the RVM were performed by slowly expelling $0.5 \mu \mathrm{l}$ of drug solution through a 33 ga injection cannula inserted through the guide cannula and protruding an additional $1 \mathrm{~mm}$ into fresh brain tissue. Dermorphin, saporin, or dermorphin-saporin was administered as a single dose of 3 pmol into the RVM (1.5 pmol in $0.5 \mu l$ on each side).

Antinociceptive testing. Response thresholds to innocuous mechanical stimuli were evaluated by determination of paw withdrawal after probing of the paw with a series of calibrated von Frey filaments. Each filament was applied perpendicularly to the plantar surface of the paw, ipsilateral to the nerve injury, of rats kept in suspended wire-mesh cages. The withdrawal threshold was determined by sequentially increasing and decreasing the stimulus strength ("up and down" method), analyzed using a Dixon nonparametric test (Dixon, 1980). Data are expressed as the mean withdrawal threshold. Response thresholds to noxious thermal stimuli were evaluated by determination of paw withdrawal from a focused beam of radiant heat. Rats were acclimated within Plexiglas enclosures on a clear glass plate, and a radiant heat source was directed onto the plantar surface of the hindpaw. Paw-withdrawal latency was determined by a motion detector. The latency to withdrawal of the paw from the radiant heat source was determined both before and after drug or vehicle administration. A maximal cutoff of $40 \mathrm{sec}$ was used to prevent tissue damage. The tail-flick test was performed by determining latency to withdrawal from a $52^{\circ} \mathrm{C}$ water bath. Data are expressed as percentage of maximal possible effect (\% MPE), which is $100 \times($ test - baseline $) /(15$ - baseline). A $15 \mathrm{sec}$ cutoff was used.

Spinal nerve injury. Spinal nerve ligation (SNL) injury was induced using the procedure of Kim and Chung (1992). Male Sprague Dawley rats (Harlan Sprague Dawley, Indianapolis, IN; 200-300 gm) were maintained in a climate-controlled room on a $12 \mathrm{hr}$ light/dark cycle and with access to food and water ad libitum. Surgery was performed in accordance with the policies and recommendations of the National Institutes of Health guidelines for the handling and use of laboratory animals and was approved by the Institutional Animal Care and Use Committee of the University of Arizona. Rats were anesthetized with halothane vaporized in $95 \% \mathrm{O}_{2} / 5 \% \mathrm{CO}_{2}$ "to effect." After surgical preparation of the rats and exposure of the dorsal vertebral column from L4 to S2, the exposed L5 and L6 spinal nerves were tightly ligated with 4-0 silk suture.
The incision was closed, and the animals were allowed to recover for $5 \mathrm{~d}$. Rats that exhibited motor deficiency or failure to exhibit subsequent increased sensitivity to innocuous mechanical stimulation were excluded from further testing ( $<5 \%$ of the animals were not used). Sham control rats underwent the same operation and handling as the experimental animals, but without SNL. Evaluation of response thresholds was performed on the hindpaw ipsilateral to SNL or sham SNL using the procedures described above.

In situ hybridization of opioid $\mu$ receptor $m R N A$. For tissue preparation, male Sprague Dawley rats were deeply anesthetized with ketamine and perfused transcardially with PBS treated with $0.1 \%$ diethylpyrocarbonate (DEPC), followed by $4 \%$ paraformaldehyde. Whole rat brains were removed and post-fixed in fixative overnight, cryoprotected in $30 \%$ sucrose in PBS treated with $0.1 \%$ DEPC, and stored at $4^{\circ} \mathrm{C}$. Frozen frontal sections $(20-40 \mu \mathrm{m})$ were prepared from the brainstem caudal to the site of incision of the cannulas and mounted on positively charged slides. A single-stranded, fluorescein-labeled partial cDNA probe corresponding to nucleotides $628-965$ of the coding region of the rat opioid $\mu$ receptor cDNA was synthesized by PCR by use of a 100:1 ratio of antisense $\left(3^{\prime}\right)$-to-sense $\left(5^{\prime}\right)$ primers and a mixture of fluorescein-labeled dUTP and unlabeled dNTP. The PCR was performed for 30 cycles $\left(45 \mathrm{sec}\right.$ at $95^{\circ} \mathrm{C}$, $60 \mathrm{sec}$ at $60^{\circ} \mathrm{C}$, and $2 \mathrm{~min}$ at $72^{\circ} \mathrm{C}$ ); the product was purified by ethanol precipitation. The probe was reconstituted in RNase-free $1 \times$ TrisEDTA and analyzed by agarose gel electrophoresis and Southern transfer to determine the yield. A corresponding sense probe was synthesized under the same conditions except using a 1:100 ratio of antisense-tosense primers, with or without fluorescein-dUTP. In situ hybridization was performed using both standard and proprietary reagents from InnoGenex (San Ramon, CA) under conditions that were caref ully optimized for our cDNA probe. Briefly, mounted tissue sections were post-fixed with $1 \%$ formaldehyde and then deproteinated with proteinase K (100 $\mu \mathrm{g} / \mathrm{ml}$ ). After a second $1 \%$ formaldehyde treatment, the sections were heated to $80^{\circ} \mathrm{C}$ for $5 \mathrm{~min}$ in a hybridization buffer containing formamide, dextran sulfate, and the fluorescein-labeled probe (typically 1:2 to $1: 5$ dilution) and allowed to cool to $37^{\circ} \mathrm{C}$, and the hybridization was continued for $16 \mathrm{hr}$ at $37^{\circ} \mathrm{C}$. The sections were washed extensively with PBS and $0.1 \%$ Tween 20 , preblocked with a buffer containing casein and sodium azide, and then incubated with a biotinylated anti-fluorescein antibody. The sections were washed, followed by incubation with a 1:3 dilution of streptavidin-alkaline phosphatase conjugate. The sections were developed by incubating with fast red for $1 \mathrm{hr}$, counterstained with Mayer's hematoxylin, and mounted with SuperMount. RNase pretreatment was performed by incubating sections with $200 \mu \mathrm{g} / \mathrm{ml}$ RNase A in $100 \mathrm{~mm}$ Tris, $\mathrm{pH} 8.0$, and $0.5 \mathrm{M} \mathrm{NaCl}$ for $60 \mathrm{~min}$ at $37^{\circ} \mathrm{C}$, followed by extensive washing before hybridization. Computer-assisted mapping was performed under bright-field illumination of coronal sections using an image-combining computer microscope using Neurolucida software (Microbrightfield Inc., Baltimore, MD). The boundaries of the facial nuclei and pyramidal tracts were manually traced using a Nikon $4 \times$ objective. The sections were then systematically scanned for labeled neurons using a Merzhauser motorized stage and a Nikon $40 \times$ objective. Bright-field images of tissue sections were acquired with a Nikon E800 microscope outfitted with a Hamamatsu C5810 color CCD camera and a $40 \times$ plan fluor 0.75 numerical aperture objective lens. The digitized output of the camera was acquired with a microcomputer.

\section{RESULTS}

\section{Binding affinity}

The radioligand binding studies in membrane preparations from NG 108-15 transfected cells that express the rat opioid $\mu$ receptors demonstrated that the conjugation of saporin to dermorphin did not significantly alter the affinity of dermorphin for opioid $\mu$ receptors. As expected, dermorphin alone demonstrated a high affinity for the $\mu$-opioid receptor and a $K_{\mathrm{i}}$ value of $0.7 \mathrm{~nm}$. The $K_{\mathrm{i}}$ value for dermorphin-saporin was $0.1 \mathrm{~nm}$.

\section{Antinociceptive activity}

The bilateral microinjection of 3 pmol of dermorphin or of dermorphin-saporin directly into the RVM produced a robust antinociceptive effect in the $52^{\circ} \mathrm{C}$ hot-water tail-flick test. The peak antinociceptive effect of dermorphin, $78 \pm 13.2 \%$ MPE, was not significantly different from that of the dermorphin-saporin 
conjugate, which was $59 \pm 4.7 \% \operatorname{MPE}(p>0.5$, Student's $t$ test). The microinjection of unconjugated saporin into the RVM did not elicit any changes in tail-flick latency.

\section{Prevention of SNL-induced neuropathic pain}

The bilateral microinjection of 3 pmol of dermorphin, saporin, or dermorphin-saporin into the RVM of naive rats produced no observable behavioral changes over a period of $28 \mathrm{~d}$. Paw withdrawal thresholds to probing with von Frey filaments remained unchanged over this time period (Fig. 1A). Similarly, the paw withdrawal latencies to radiant heat applied to the plantar aspect of the hindpaw did not change over this $28 \mathrm{~d}$ period (Fig. 1B). Furthermore, the nociceptive tail-flick reflex to $52^{\circ} \mathrm{C}$ water immersion was also unaffected in these experimental animals (Fig. 1C).

The same group of rats then underwent either sham or SNL surgery and was tested again $7 \mathrm{~d}$ after surgery. The rats that initially received either saporin or dermorphin alone demonstrated a clear development of behavioral signs of neuropathic pain associated with SNL (Fig. 2). Rats receiving SNL and either RVM dermorphin or saporin alone displayed tactile allodynia and thermal hyperalgesia as evidenced by a significant reduction in paw withdrawal thresholds (Fig. $2 A$ ). Likewise, the paw withdrawal latencies for the dermorphin- and saporin-pretreated groups were significantly $(p \leq 0.05)$ decreased $7 \mathrm{~d}$ after SNL (Fig. 2B). In contrast, the dermorphin-saporin-pretreated SNL group showed responses to non-noxious or noxious stimuli that did not differ significantly from the pre-SNL baseline values in response either to probing with von Frey filaments or to noxious radiant heat (Fig. 2). The responses of the sham-operated rats did not demonstrate any evidence of neuropathic pain behavior with either probing with von Frey filaments or noxious radiant heat.

\section{Prevention of neuropathic pain}

The paw withdrawal thresholds to probing with von Frey filaments and the latencies to withdrawal from noxious radiant heat were determined before any manipulations. The pooled paw withdrawal thresholds were $12.6 \pm 0.88 \mathrm{gm}$, and the pooled paw withdrawal latencies were $20 \pm 1.15 \mathrm{sec}$ (Fig. 3). Rats with either SNL or sham surgery were randomly separated into three groups each destined for microinjection of dermorphin, saporin, or dermorphin-saporin into the RVM. Rats with SNL showed clear behavioral signs of neuropathic pain on the fifth day after surgery. Tactile allodynia was indicated by the significant $(p \leq 0.05)$ reductions in the paw withdrawal thresholds of rats with SNL to innocuous mechanical light touch (Fig. 3A). Thermal hyperalgesia was indicated in rats with SNL by the significant $(p \leq 0.05)$ reduction in paw withdrawal latencies to noxious radiant heat (Fig. 3B). After these baseline determinations were made, rats received 3 pmol of dermorphin, saporin, or dermorphin-saporin bilaterally into the RVM. Animals were tested at 2, 7, 14, and $28 \mathrm{~d}$ after the microinjections. Rats with SNL that received the dermorphin-saporin conjugate demonstrated a gradual loss of heightened sensitivity to both innocuous mechanical and noxious thermal stimuli over the $28 \mathrm{~d}$ observation period (Fig. 3). On day 28 , the paw withdrawal thresholds to probing with von Frey filaments were significantly ( $p \leq 0.05$ ) elevated and not significantly different $(p>0.05)$ from preligation values (Fig. $3 A)$ in rats with SNL. Similarly, paw withdrawal latencies to noxious radiant heat were not significantly $(p \leq 0.05)$ different from pre-SNL values $28 \mathrm{~d}$ after the microinjection of dermorphinsaporin (Fig. 3B). The microinjection of 3 pmol of either dermor-

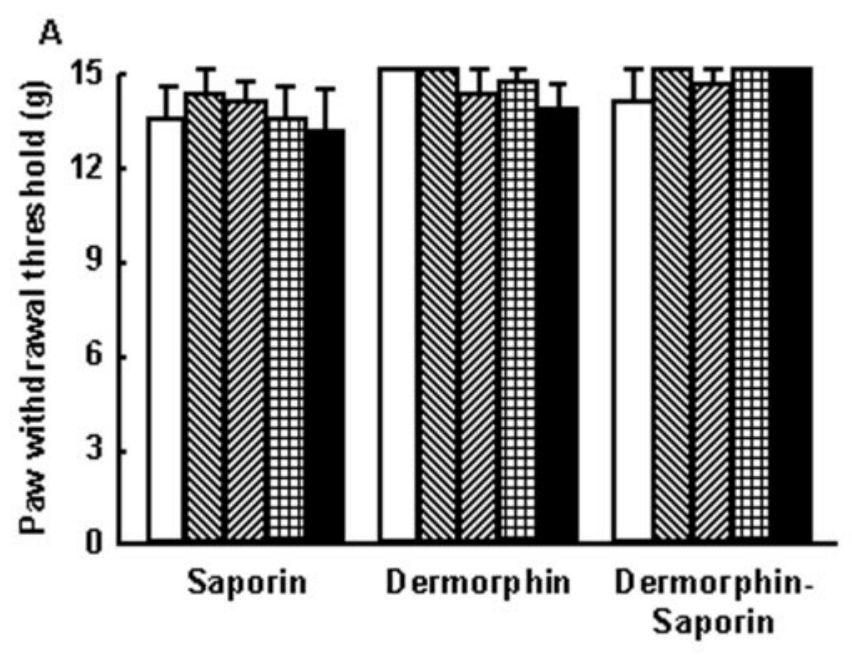

ש Baseline w Day 2 Day 7 Day 14 Day 28

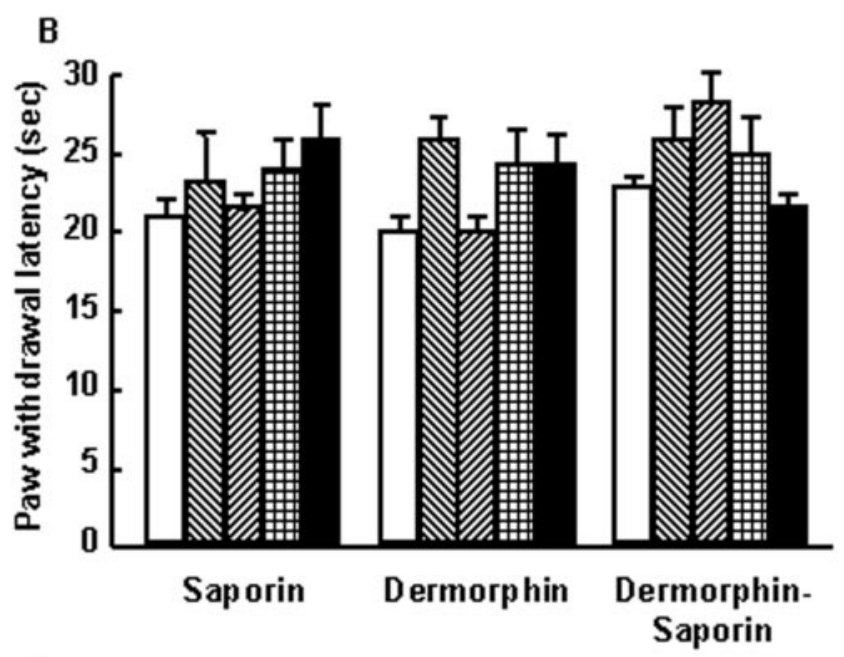

C

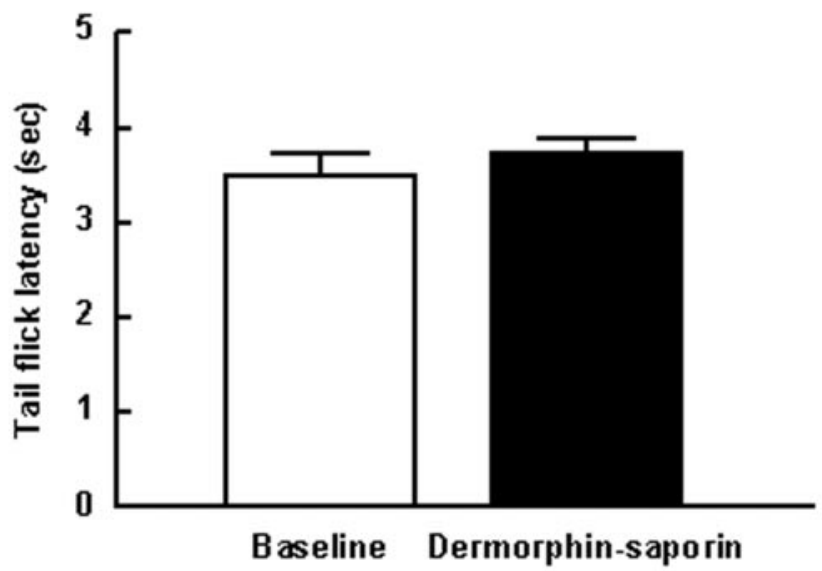

Figure 1. Male Sprague Dawley rats received a bilateral microinjection of saporin, dermorphin, or dermorphin-saporin into the RVM. $A, B$, The animals were tested for responses to non-noxious mechanical stimuli (von Frey filaments) $(A)$ and to noxious radiant heat $(B)$ on days 0 (baseline), $2,7,14$, and 28 after the microinjection. No significant changes $(p>0.05)$ were observed in any of the groups of rats over this observation period (ANOVA). $C$, The response latency to noxious heat applied to the tail (tail-flick reflex using a $52^{\circ} \mathrm{C}$ water bath) was also determined before dermorphin-saporin and again at day 28 after the microinjection; no change in response latencies was observed. $n=6$ rats per group. 
A

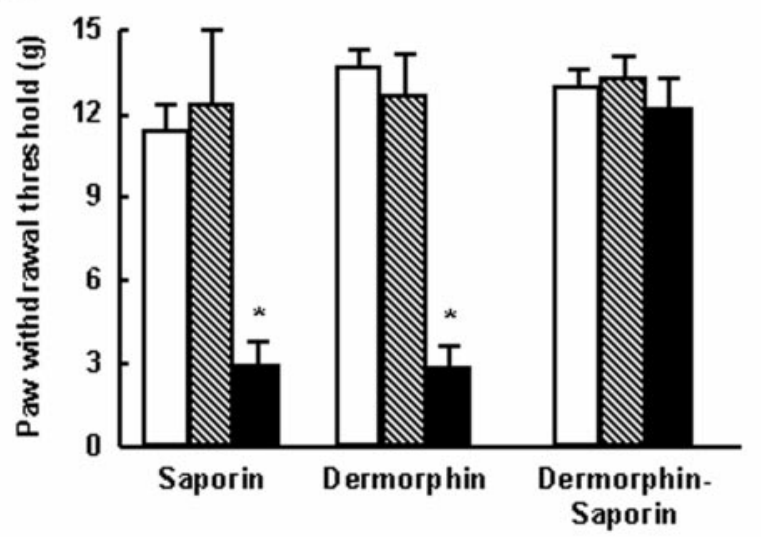

B
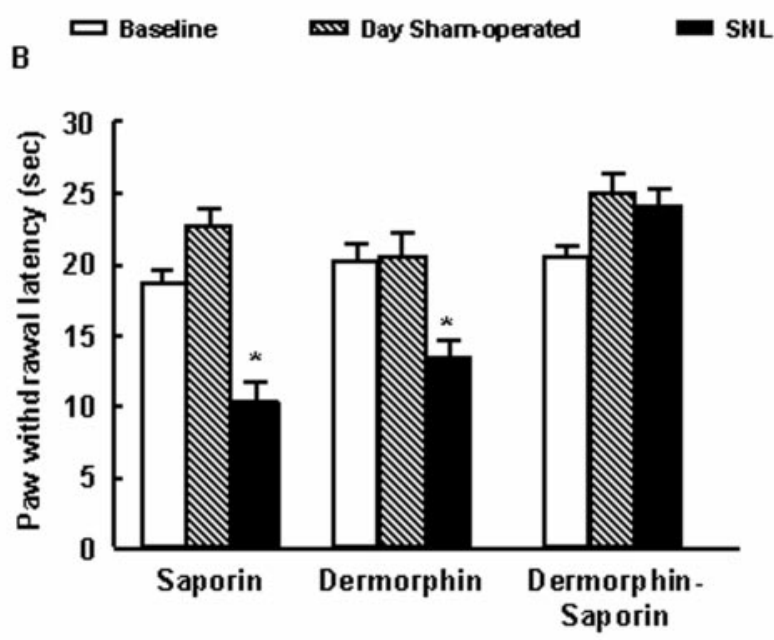

Figure 2. Male Sprague-Dawley rats received a bilateral microinjection of saporin, dermorphin, or dermorphin-saporin into the RVM. After $28 \mathrm{~d}$, rats were subjected to either SNL or sham surgery. Seven days after surgery, the animals were tested for their responsivity to normally nonnoxious mechanical $(A)$ or noxious thermal $(B)$ stimuli applied to the paw ipsilateral to the sham or SNL procedure. Rats that had received RVM pretreatment of either saporin or dermorphin demonstrated increased sensitivity to both normally non-noxious mechanical and noxious thermal stimuli after SNL, as indicated by the significantly $\left({ }^{*} p \leq 0.05\right.$, Student's $t$ test) decreased thresholds to these stimuli when compared with the pretreatment baseline levels. However, rats with SNL that were pretreated with RVM dermorphin-saporin showed response thresholds to mechanical or thermal stimuli that were not significantly different from baseline values $(p>0.05)$. None of the sham SNL groups demonstrated any appreciable changes in behavioral responses when compared with the pretreatment baseline after any RVM pretreatment.

phin or saporin alone did not effect any changes in the behavioral responses to light tactile or noxious thermal stimuli. On day 28 after the microinjection of dermorphin or saporin into the RVM, the paw withdrawal thresholds and latencies of the rats with SNL were essentially unchanged and significantly lower than pre-SNL values $(p>0.05)$ (Fig. 3$)$.

\section{Blockade with $\beta$-funaltrexamine}

Groups of six male Sprague Dawley rats were tested for acute antinociception using the $52^{\circ} \mathrm{C}$ warm-water tail-flick test after RVM dermorphin (3 pmol), U69,593 (60 nmol), or [D-Ala ${ }^{2}$, $\mathrm{Glu}^{4}$ ]deltorphin $(60 \mathrm{nmol})$. These opioids produced an acute antinociceptive effect of $95 \pm 4.4,54 \pm 14$, or $63 \pm 9 \% \mathrm{MPE}$, respectively. The rats were allowed to rest for $7 \mathrm{~d}$, and each then

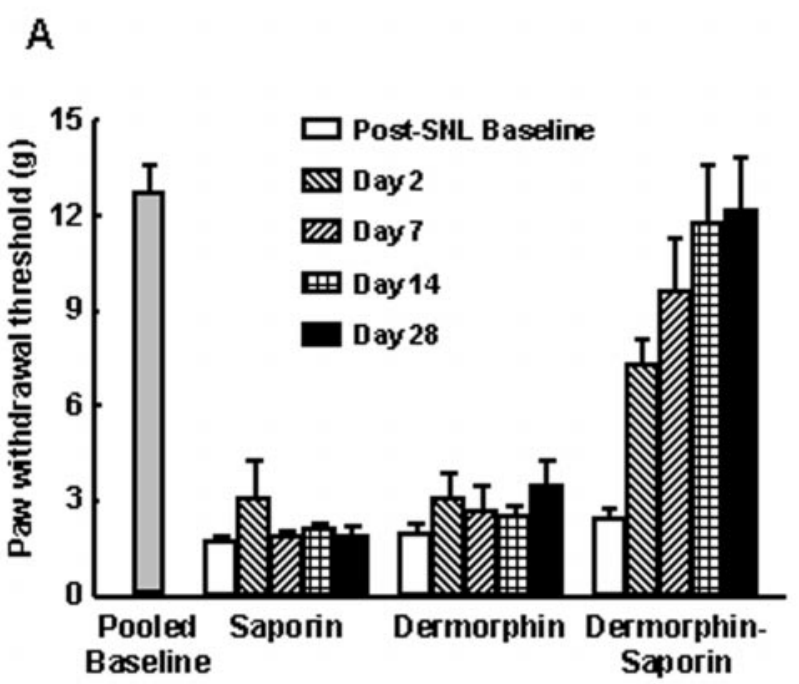

B

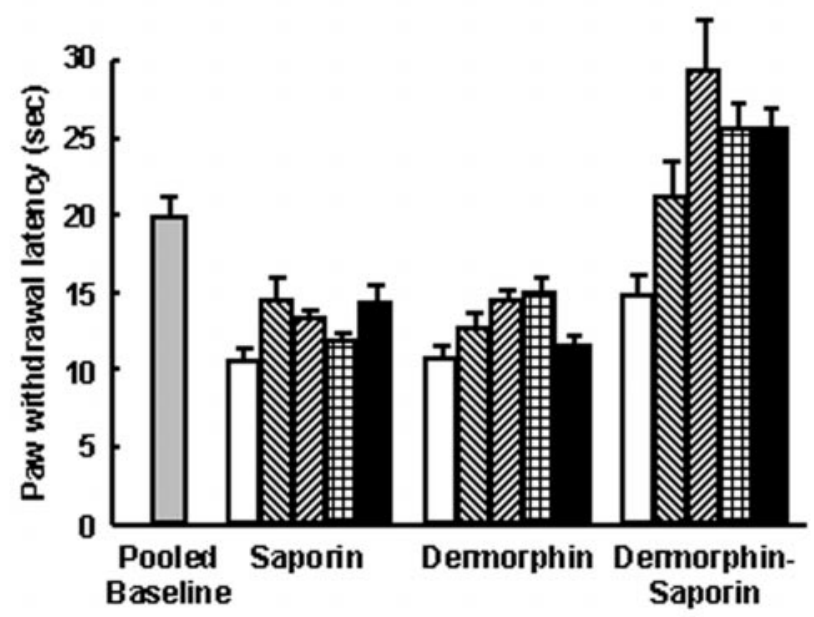

Figure 3. Baseline responses to von Frey filaments and to noxious radiant heat were determined in male Sprague Dawley rats. The rats were then subjected to SNL. After increased sensitivity to normally nonnoxious mechanical $(A)$ and noxious thermal $(B)$ stimuli was clearly established in the SNL rats, they were divided into equal groups and received RVM microinjections of saporin, dermorphin, or dermorphinsaporin. The animals were tested for the response threshold to normally non-noxious mechanical $(A)$ and noxious thermal stimuli $(B)$ over a $28 \mathrm{~d}$ period. By approximately day 2 after the injection, all groups of SNL rats demonstrated clearly increased sensitivity to normally non-noxious mechanical and noxious thermal stimuli, as indicated by significantly reduced behavioral response thresholds compared with the pretreatment baseline levels ( $p \leq 0.05$, Student's $t$ test). By postinjection day 8 , however, and continuing to the end of the experiment at day 28 , the SNL rats that received an RVM microinjection of dermorphin-saporin exhibited a progressive reversal of both mechanical $(A)$ and thermal $(B)$ thresholds to levels that did not differ significantly from baseline $(p>0.05)$. SNL rats that received dermorphin or saporin retained both behavioral signs of experimental neuropathic pain. $n=6$ rats per group.

was given an injection of an opioid $\mu$ receptor-selective dose of $18.8 \mathrm{nmol}$ of $\beta$-funaltrexamine ( $\beta$-FNA) bilaterally $(9.4 \mathrm{nmol}$ in $0.5 \mu \mathrm{l}$ on each side) into the RVM. Each group of rats was then tested $24 \mathrm{hr}$ later for acute antinociception with the same dose of receptor-selective opioid as before. Pretreatment with $\beta$-FNA did not affect baseline latencies to tail flick when measured $24 \mathrm{hr}$ after 
administration but significantly inhibited the acute antinociception of RVM dermorphin as indicated by an antinociceptive index of only $9.7 \pm 5.6 \%$ MPE. In contrast, the antinociceptive effects of RVM U69,593 or of RVM [D-Ala ${ }^{2}, \mathrm{Glu}^{4}$ ]deltorphin were not changed by pretreatment with $\beta$-FNA. The antinociceptive indices obtained were $48 \pm 8.8$ and $61 \pm 10 \% \mathrm{MPE}$ after $\beta$-FNA, respectively, values not significantly different from control $(p>$ $0.05)$. These data ensure that the dose of $\beta$-FNA used was selective for the $\mu$-opioid but not the $\kappa$ - or $\delta$-opioid receptors.

The same dose, $18.8 \mathrm{nmol}$ of $\beta$-FNA, was microinjected bilaterally into the RVM of naive rats. After $24 \mathrm{hr}$, the rats received RVM microinjections of 3 pmol of dermorphin, saporin, or dermorphin-saporin conjugate. After $28 \mathrm{~d}$, the animals were subjected to SNL and evaluated for responses to innocuous mechanical and noxious thermal stimuli $7 \mathrm{~d}$ later. The groups that received $\beta$-FNA pretreatment before saporin, dermorphin, or dermorphin-saporin all exhibited increased sensitivity to innocuous mechanical (Fig. 4A) and noxious thermal (Fig. 4B) stimuli as expected with SNL. In contrast, SNL rats that received saline before the dermorphin-saporin conjugate did not show any behavioral signs of neuropathic pain. The paw withdrawal thresholds to von Frey filaments (Fig. $4 A$ ) and the latencies to noxious radiant heat (Fig. $4 B$ ) were not significantly different from the pretreatment baseline values.

\section{In situ hybridization}

Our initial analysis using coronal sections from the brainstem region of naive rats (taken between -11.0 and $-13.2 \mathrm{~mm}$ from bregma) showed that the localization of cells expressing $\mu$-opioid receptor transcripts in the caudal brainstem including the RVM was highly consistent with that reported previously based on autoradiography for the receptor or on in situ hybridization for message (Bowker and Dilts, 1988; Bowker et al., 1988; Mansour et al., 1994a,b; Peckys and Landwehrmeyer, 1999). In the RVM, cells that expressed opioid $\mu$ receptor transcripts were highly localized to the raphe magnus and the magnocellular reticular nucleus and also found at a lower cell density in the paragigantocellular reticular nucleus-lateral part and the gigantocellular reticular nucleus. Caudal to the RVM, $\mu$ receptor transcripts were highly localized to cells in the raphe obscurus, the raphe pallidus, the inferior olivary complex, the external nucleus cuneatus, the medial solitary nucleus, the hypoglossal nucleus, the dorsal motor nucleus of the vagus, the spinal trigeminal tract, and the nucleus ambiguus. A low density of discrete cell bodies in the nucleus gigantoreticular nucleus was also labeled. The localization of the cells that express $\mu$ receptor mRNA is consistent with that described previously. For the experiments, coronal sections $20 \mu \mathrm{m}$ thick were obtained $28 \mathrm{~d}$ after the bilateral microinjection of dermorphin, saporin, or dermorphin-saporin into the RVM. The brain slices obtained from rats that had been pretreated with dermorphin or saporin alone showed similar densities of labeling for mRNA of the $\mu$-opioid receptor in the RVM (Fig. 5). The RVM of the dermorphin-saporin-pretreated rats consists of significantly fewer labeled cells when compared with that of dermorphin- or saporin-pretreated rats (Fig. 5). This regional loss of $\mu$ receptor transcripts in dermorphin-saporin-pretreated tissues was not caused by differences in experimental conditions because the processing of tissues and the in situ hybridization procedures were performed in parallel with tissues from dermorphin- or saporin-pretreated rats. Furthermore, brainstem sections caudal to the RVM (between -12.2 and $-13.2 \mathrm{~mm}$ from bregma) taken from dermorphin-, saporin-, or dermorphin-
A

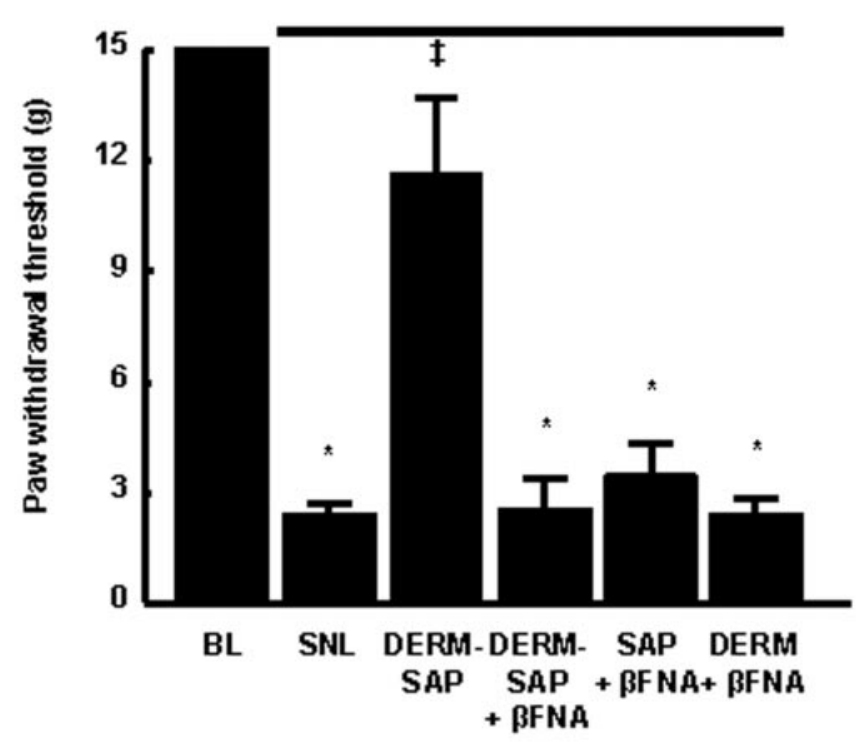

B

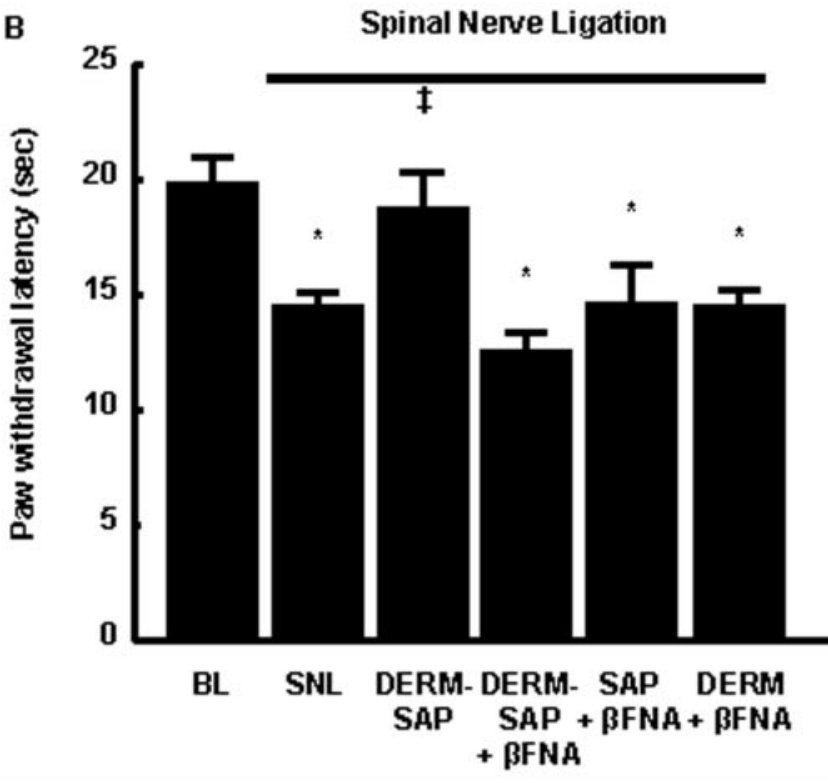

Figure 4. Male Sprague Dawley rats were tested for threshold responses to non-noxious mechanical or noxious thermal stimuli (baseline values) and subsequently received either the noncompetitive opioid $\mu$ receptor antagonist $\beta$-FNA or saline into the RVM 24 hr before the administration of saporin, dermorphin, or dermorphin-saporin into the RVM. All groups were subjected to SNL 28 d after RVM dermorphin, saporin, or dermorphin-saporin and tested for their response thresholds to nonnoxious mechanical or noxious thermal stimuli $7 \mathrm{~d}$ after SNL surgery. Pretreatment with $\beta$-FNA before RVM dermorphin-saporin abolished the ability of RVM dermorphin-saporin to prevent SNL-induced increased sensitivity to non-noxious mechanical and noxious thermal stimuli but did not alter the effects of SNL in saporin- or dermorphin-pretreated rats. $n=6$ rats per group. $B L$, Baseline; DERM, dermorphin; $S A P$, saporin. * $p \leq 0.05$ from baseline; $\ddagger p \leq 0.05$ from SNL.

saporin-pretreated animals showed similar distributions and densities of labeled cells, suggesting that the loss of labeling correlates with the stereotaxic delivery of dermorphin-saporin to the RVM and that this loss is specific to dermorphin-saporin treatment (data not shown). The immunolabeling could be abolished by pretreatment of the tissue sections with RNase or by an excess 
A

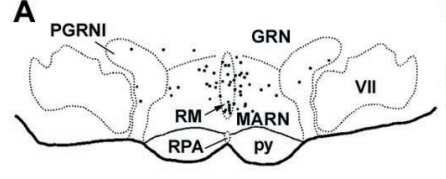

B
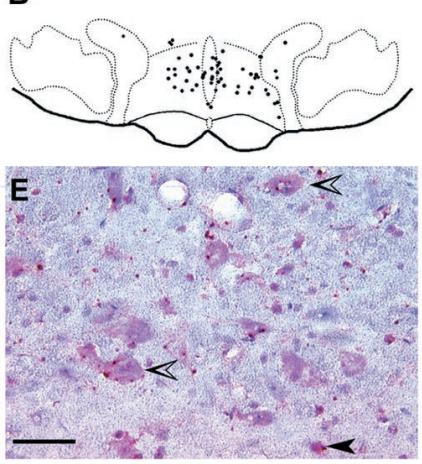

C
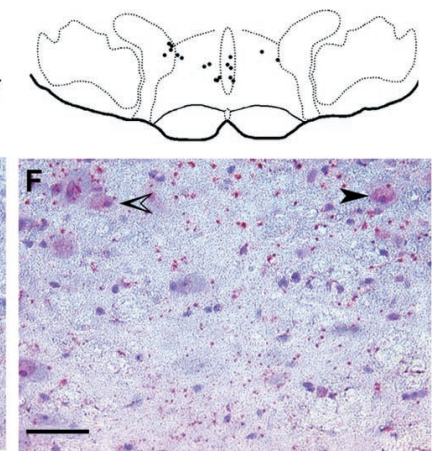

Figure 5. Localization of opioid $\mu$ receptor mRNA in frontal sections $(20 \mu \mathrm{m})$ of the brainstem at the level of the caudal raphe nuclei (approximately $-11.0 \mathrm{~mm}$ from bregma) by a colorimetric immunodetection method using a fluorescein-labeled, partial cDNA probe generated from the coding region of the rat MOR. Hybridized probe was detected by an anti-fluorescein antibody. Bright-field micrographs $(D-F)$ show the distribution of the probe as a red stain (fast red). The sections were counterstained with Mayer's hematoxylin (blue nuclei). Computer-assisted mapping of representative sections shows the location of opioid $\mu$ receptor mRNA-labeled cells $($ dots $)$ in the RVM of rats that had been pretreated with dermorphin $(A)$, saporin $(B)$, or dermorphin-saporin $(C)$ and the corresponding high-magnification, bright-field micrographs $(D-F)$ taken from the same area in the raphe magnus (denoted by arrow in $A$ ) of $A-C$, respectively. The cDNA probe labeled discrete neuronal cell bodies. Two types of staining by fast red are seen, (1) perinuclear staining (closed arrowheads) and (2) cytoplasmic staining (open arrowheads). Unlabeled cells can be seen as blue nuclei with negligible or very light blue cytoplasmic stain. In the RVM, cells that expressed opioid $\mu$ receptor transcripts were highly localized to the $R M$ and the $M A R N$ and also found at a lower cell density in the $P G R N l$ and the GRN. The localization of the cells that express $\mu$ receptor mRNA is consistent with that described previously. The RVM of dermorphin-saporin-pretreated rats $(C, F)$ consists of significantly fewer labeled cells when compared with that of dermorphin-pretreated $(A, D)$ or saporin-pretreated $(B, E)$ rats. The specificity of the labeling for $\mu$-opioid receptor transcripts is also supported by the consistency in the distribution pattern of labeling across multiple brainstem sections and sections from multiple animals. This labeling could be abolished by RNase A pretreatment of the tissue sections or by the presence of an unlabeled, corresponding sense DNA during hybridization. GRN, Gigantocellular reticular nucleus; $M A R N$, magnocellular reticular nucleus; PGRNl, paragigantocellular reticular nucleus-lateral part; $p y$, pyramidal tract; $R M$, raphe magnus; $R P A$, raphe pallidus; VII, facial nucleus. Scale bars, $50 \mu \mathrm{m}$.

of the complementary sense DNA during the hybridization reaction. The histological staining of the tissue sections indicates that tissue necrosis was negligible. Thus, a selective degeneration of $\mu$-receptor-expressing cells in the RVM by dermorphin-saporin prevented abnormal pain resulting from SNL, without affecting normal sensory responses.

\section{DISCUSSION}

Mechanistic interpretation of the neuropathic state has generally focused on injury-induced changes in peripheral nerves and in the spinal dorsal horn. Spinal sensitization is believed to occur as a consequence of the increased firing of primary afferent fibers and has been thought to be a key element in nerve injury-induced pain (Wall and Gutnick, 1974; Devor, 1991, 1994; Kajander et al., 1992; Fields et al., 1997). The time course of increased discharge from injured nerves does not appear to correlate perfectly, however, with the sustained nature of nerve injury-induced pain. Although nerve injury-induced pain is sustained essentially unchanged for many weeks (Chaplan et al., 1994; Bian et al., 1995), data from several groups show that the discharge rate of injured afferents declines significantly over just a few days after the injury (Han et al., 2000; Liu et al., 2000). Large myelinated fibers are spontaneously active in the postinjury state, and uninjured adjacent fibers also discharge tonically (Boucher et al., 2000; Li et al., 2000; Wu et al., 2001). The known projections of these fibers to the brainstem, along with the observations of plasticity at levels as far rostral as the midbrain after injury to peripheral nerves (Kovelowski et al., 2000), point to a role of supraspinal sites in the nerve injury-induced pain state. This concept is supported by various lesion studies of ascending pathways (Houghton et al., 1999; Sun et al., 2001) as well as by the emergence of evidence of the critical importance of descending pain facilitation pathways in nerve injury-induced pain. Specifically, blockade of nerve injuryinduced pain is seen after RVM microinjection of lidocaine
(Pertovaara et al., 1996; Kovelowski et al., 2000) as well as by lesions of the DLF (Ossipov et al., 2000).

The results of the present study suggest that a specific population of RVM neurons, namely, those expressing opioid $\mu$ receptors, is critical in the behavioral expression of experimental neuropathic pain. These RVM cells display characteristics consistent with those characterized previously as facilitatory or pronociceptive. The electrophysiologic characteristics of the neurons of this region have been well characterized and strongly point to this region as a likely source of facilitation of nociceptive input (Fields et al., 1983; Fields and Heinricher, 1985; Fields, 1992). One neuronal class, labeled "ON" cells because of a firing burst recorded just before activation of a nocifensive response, is believed responsible for descending facilitation of nociception via both local interactions within the RVM and descending systems projecting to the spinal cord (Fields et al., 1991; Heinricher et al., 1992; Heinricher and Roychowdhury, 1997). Manipulations that increase nociceptive responsiveness, thus indicating facilitation, also increase ON cell activity (Heinricher et al., 1989; Kaplan and Fields, 1991; Morgan and Fields, 1994; Fields and Basbaum, 1999). Importantly, this class of neurons is hypothesized to represent the population of $\mu$-opioid receptor-expressing cells. In agreement with this hypothesis, systemic or RVM morphine produces a naloxone-sensitive depression in spontaneous and evoked firing rates of identified ON cells (Heinricher et al., 1992), whereas the firing characteristics of other RVM neurons are not affected by the opiate (Heinricher et al., 1992). Analogous studies in vitro show that RVM $\mu$-opioid agonists directly hyperpolarize "secondary cells" (Pan et al., 1990). Such findings suggest that ON cells are likely to be the only $\mu$-opioid receptor-expressing cells in the RVM (Heinricher et al., 1992).

Our data show that conjugated dermorphin-saporin retains affinity and efficacy at the opioid $\mu$ receptor, suggesting that this 
molecule is suitable for targeting cells that express these receptors. Selective loss of $\mu$-opioid-containing neurons was demonstrated by a significant decrease in the number of cells positively labeled for $\mu$ receptor transcript in animals pretreated with dermorphin-saporin but not with dermorphin or saporin. Rats treated with RVM dermorphin or saporin demonstrated an equivalent presence of labeling for $\mu$-opioid mRNA. Neurons that were not in the vicinity of the site of dermorphin-saporin injection were spared, however, suggesting that the loss of $\mu$-opioid receptor-expressing cells was not the result of a nonselective cytotoxicity or because of trauma resulting from cannula implantation or microinjection.

RVM microinjection of dermorphin-saporin, or of unconjugated saporin or dermorphin, did not produce any significant changes in response thresholds to normally non-noxious mechanical or noxious thermal stimuli of the paw when evaluated over a 28 d time course. Because a significant depletion of cells expressing $\mu$-opioid receptor transcript was seen in animals injected with RVM dermorphin-saporin, it appears that $\mu$-opioid receptorexpressing cells do not participate in the response to non-noxious or noxious sensory thresholds. Subsequent experimental nerve injury, however, showed that although rats pretreated with RVM dermorphin or saporin developed the expected increased sensitivity to normally non-noxious mechanical and noxious thermal stimuli, those animals pretreated with RVM dermorphin-saporin did not. These findings indicate that depletion of RVM cells expressing $\mu$-opioid receptors, presumably cells that mediate descending facilitation to the spinal dorsal horn, prevents the expected neuropathic pain state. In the absence of electrophysiological investigation, it is unknown whether such lesioned cells represent the previously characterized population of RVM cells referred to as ON cells. The specificity of dermorphin-saporin for RVM cells expressing $\mu$-opioid receptors was confirmed by the use of $\beta$-FNA, a selective and irreversible $\mu$-opioid receptor antagonist (Ward et al., 1982; Jiang et al., 1990). RVM microinjection of $\beta$-FNA was shown to antagonize the antinociceptive effects of a receptor-selective opioid $\mu$, but not selective $\delta$ or $\kappa$, agonist indicating that the dose administered selectively blocked $\mu$-opioid receptors; the selectivity of the antagonist is supported by similar results in previous studies (Tiberi et al., 1988; Melchiorri et al., 1991). Administration of RVM dermorphin-saporin in rats pretreated with $\beta$-FNA showed that the expected prevention of nerve injury-induced pain was blocked; $\beta$-FNA pretreatment did not alter the development of nerve injury-induced pain in groups pretreated with either dermorphin or saporin.

In addition to the observation of prevention of nerve injuryinduced pain by RVM pretreatment with dermorphin-saporin, our data also demonstrate that the behavioral signs of experimental neuropathic pain can be reversed by targeting $\mu$-opioid receptor-expressing cells in this region. Administration of dermorphin-saporin, but not of dermorphin or saporin, showed a time-related return to normal levels of sensitivity to non-noxious mechanical or to noxious thermal stimuli in nerve-injured rats. The reversal of established experimental neuropathic pain demonstrates the importance of descending facilitation in sustaining pain. Together, these observations suggest a requirement for RVM $\mu$ receptor-expressing cells for the expression and maintenance of nerve injury-induced pain. The data indicate the importance of such cells under pathological, but not normal physiological, conditions because reactions to light touch or to acute noxious stimuli are unaltered in uninjured or sham-operated rats. These findings are consistent with previous observations indicat- ing a role for supraspinal mechanisms of neuropathic pain (Mansikka and Pertovaara, 1997; Bian et al., 1998; Pertovaara, 1998; Kovelowski et al., 2000; Ossipov et al., 2000; Sun et al., 2001) and are in agreement with data resulting from experiments with more generalized and reversible blockade of RVM activity such as lidocaine injection (Pertovaara et al., 1996; Kovelowski et al., 2000). Finally, the data of the present study are consistent with observations showing reversal of nerve injury-induced pain by physical disruption of the DLF (Ossipov et al., 2000).

The results presented here are consistent with the hypothesis that the presence and activity of descending pain facilitation cells in the RVM are required for the expression of experimental neuropathic pain. Furthermore, these neurons are likely to be the $\mu$-opioid receptor-expressing cells of the RVM. Because dermorphin-saporin was shown to be effective in reversing established experimental pain, the $\mu$-opioid-expressing neurons should therefore represent an appropriate target for the development of strategies for the treatment of abnormal pain states. It is clearly more important to be able to treat established neuropathic pain, because one cannot anticipate its development. Critically, targeting mechanisms of descending pain facilitation offers a novel approach to the alleviation of chronic, pathological pain that does not alter normal sensitivity to innocuous or noxious sensations. These observations raise many important questions including the nature of the tonic activation in the RVM that drives descending facilitatory systems and the spinal circuitry by which such projections facilitate the transmission of pain. Increased understanding of underlying mechanisms that may drive abnormal pain would be relevant to the formulation of novel treatment protocols.

\section{REFERENCES}

Bennett GJ, Xie YK (1988) A peripheral mononeuropathy in rat that produces disorders of pain sensation like those seen in man. Pain 33:87-107.

Bian D, Nichols ML, Ossipov MH, Lai J, Porreca F (1995) Characterization of the antiallodynic efficacy of morphine in a model of neuropathic pain in rats. NeuroReport 6:1981-1984.

Bian D, Ossipov MH, Zhong C, Malan Jr TP, Porreca F (1998) Tactile allodynia, but not thermal hyperalgesia, of the hindlimbs is blocked by spinal transection in rats with nerve injury. Neurosci Lett 241:79-82.

Boucher TJ, Okuse K, Bennett DL, Munson JB, Wood JN, McMahon SB (2000) Potent analgesic effects of GDNF in neuropathic pain states. Science 290:124-127.

Bowker RM, Dilts RP (1988) Distribution of mu-opioid receptors in the nucleus raphe magnus and nucleus gigantocellularis: a quantitative autoradiographic study. Neurosci Lett 88:247-252.

Bowker RM, Abbott LC, Dilts RP (1988) Peptidergic neurons in the nucleus raphe magnus and the nucleus gigantocellularis: their distributions, interrelationships, and projections to the spinal cord. Prog Brain Res 77:95-127.

Braga PC, Tiengo M, Biella G, Dall'Oglio G, Fraschini F (1984) Dermorphin, a new peptide from amphibian skin, inhibits the nociceptive thalamic neurons firing rate evoked by noxious stimuli. Neurosci Lett $52: 165-169$

Broccardo M, Erspamer V, Falconieri Erspamer G, Improta G, Linari G, Melchiorri P, Montecucchi PC (1981) Pharmacological data on dermorphins, a new class of potent opioid peptides from amphibian skin. Br J Pharmacol 73:625-631.

Chaplan SR, Sorkin LS (1997) Agonizing over pain terminology. Pain Forum 6:81-87.

Chaplan SR, Bach FW, Pogrel JW, Chung JM, Yaksh TL (1994) Quantitative assessment of tactile allodynia in the rat paw. J Neurosci Methods 53:55-63.

Devor M (1991) Neuropathic pain and injured nerve: peripheral mechanisms. Br Med Bull 47:619-630.

Devor M (1994) The pathophysiology of damaged peripheral nerves. In: Textbook of pain (Wall PD, Melzack R, eds), pp 79-100. Edinburgh: Livingstone.

Dixon WJ (1980) Efficient analysis of experimental observations. Annu Rev Pharmacol Toxicol 20:441-462.

Fields HL (1992) Is there a facilitating component to central pain modulation? APS J 1:71-78.

Fields HL, Basbaum AI (1999) Central nervous system mechanisms of 
pain modulation. In: Textbook of pain, Ed 4 (Wall PD, Melzack R, eds), pp 309-329. Edinburgh: Livingstone.

Fields HL, Heinricher MM (1985) Anatomy and physiology of a nociceptive modulatory system. Philos Trans R Soc Lond B Biol Sci 308:361-374.

Fields HL, Heinricher MM (1989) Brainstem modulation of nociceptordriven withdrawal reflexes. Ann NY Acad Sci 563:34-44.

Fields HL, Bry J, Hentall I, Zorman G (1983) The activity of neurons in the rostral medulla of the rat during withdrawal from noxious heat. J Neurosci 3:2545-2552.

Fields HL, Heinricher MM, Mason P (1991) Neurotransmitters in nociceptive modulatory circuits. Annu Rev Neurosci 14:219-245.

Fields HL, Rowbotham MC, Devor M (1997) Excitability blockers: anticonvulsants and low concentration local anesthetics in the treatment of chronic pain. In: Handbook of experimental pharmacology (Dickenson A, Besson JM, eds), pp 93-116. Berlin: Springer.

Han HC, Lee DH, Chung JM (2000) Characteristics of ectopic discharges in a rat neuropathic pain model. Pain 84:253-261.

Heinricher MM, Roychowdhury SM (1997) Reflex-related activation of putative pain facilitating neurons in rostral ventromedial medulla requires excitatory amino acid transmission. Neuroscience 78:1159-1165.

Heinricher MM, Barbaro NM, Fields HL (1989) Putative nociceptive modulating neurons in the rostral ventromedial medulla of the rat: firing of on- and off-cells is related to nociceptive responsiveness. Somatosens Motor Res 6:427-439.

Heinricher MM, Morgan MM, Fields HL (1992) Direct and indirect actions of morphine on medullary neurons that modulate nociception. Neuroscience 48:533-543.

Heinricher MM, Morgan MM, Tortorici V, Fields HL (1994) Disinhibition of off-cells and antinociception produced by an opioid action within the rostral ventromedial medulla. Neuroscience 63:279-288.

Houghton AK, Hewitt E, Westlund KN (1999) Dorsal column lesion prevents mechanical hyperalgesia and allodynia in osteotomy model. Pain 82:73-80.

Jiang Q, Heyman JS, Sheldon RJ, Koslo RJ, Porreca F (1990) Mu antagonist and kappa agonist properties of beta-funaltrexamine (betaFNA) in vivo: long-lasting spinal analgesia in mice. J Pharmacol Exp Ther 252:1006-1011.

Kajander KC, Wakisaka S, Bennett GJ (1992) Spontaneous discharge originates in the dorsal root ganglion at the onset of a painful peripheral neuropathy in the rat. Neurosci Lett 138:225-228.

Kaplan H, Fields HL (1991) Hyperalgesia during acute opioid abstinence: evidence for a nociceptive facilitating function of the rostral ventromedial medulla. J Neurosci 11:1433-1439.

Kim KJ, Yoon YW, Chung JM (1997) Comparison of three rodent neuropathic pain models. Exp Brain Res 113:200-206.

Kim SH, Chung JM (1992) An experimental model for peripheral neuropathy produced by segmental spinal nerve ligation in the rat. Pain 50:355-363.

Kirk EJ (1974) Impulses in dorsal spinal nerve rootlets in cats and rabbits arising from dorsal root ganglia isolated from the periphery. J Comp Neurol 155:165-175.

Kovelowski CJ, Ossipov MH, Sun H, Lai J, Malan TP, Porreca F (2000) Supraspinal cholecystokinin may drive tonic descending facilitation mechanisms to maintain neuropathic pain in the rat. Pain 87:265-273.

Li Y, Dorsi MJ, Meyer RA, Belzberg AJ (2000) Mechanical hyperalgesia after an L5 spinal nerve lesion in the rat is not dependent on input from injured nerve fibers. Pain 85:493-502.

Liu X, Eschenfelder S, Blenk KH, Janig W, Habler H (2000) Spontaneous activity of axotomized afferent neurons after L5 spinal nerve injury in rats. Pain 84:309-318.

Mansikka H, Pertovaara A (1997) Supraspinal influence on hindlimb withdrawal thresholds and mustard oil-induced secondary allodynia in rats. Brain Res Bull 42:359-365.

Mansour A, Fox CA, Thompson RC, Akil H, Watson SJ (1994a) Muopioid receptor mRNA expression in the rat CNS: comparison to mu-receptor binding. Brain Res 643:245-265.
Mansour A, Fox CA, Burke S, Meng F, Thompson RC, Akil H, Watson SJ (1994b) Mu, delta, and kappa opioid receptor mRNA expression in the rat CNS: an in situ hybridization study. J Comp Neurol 350:412-438.

Mantyh PW, Rogers SD, Honore P, Allen BJ, Ghilardi JR, Li J, Daughters RS, Lappi DA, Wiley RG, Simone DA (1997) Inhibition of hyperalgesia by ablation of lamina I spinal neurons expressing the substance P receptor. Science 278:275-279.

Mason Jr DJ, Lowe J, Welch SP (1999) Cannabinoid modulation of dynorphin A: correlation to cannabinoid-induced antinociception. Eur J Pharmacol 378:237-248.

Melchiorri P, Negri L, Falconieri-Erspamer G, Severini C, Corsi R, Soaje M, Erspamer V, Barra D (1991) Structure-activity relationships of the delta-opioid-selective agonists, deltorphins. Eur J Pharmacol 195:201-207.

Morgan MM, Fields HL (1994) Pronounced changes in the activity of nociceptive modulatory neurons in the rostral ventromedial medulla in response to prolonged thermal noxious stimuli. J Neurophysiol 72:1161-1170.

Nichols ML, Allen BJ, Rogers SD, Ghilardi JR, Honore P, Luger NM, Finke MP, Li J, Lappi DA, Simone DA, Mantyh PW (1999) Transmission of chronic nociception by spinal neurons expressing the substance P receptor. Science 286:1558-1561.

Ossipov MH, Sun H, Malan TP, Lai J, Porreca F (2000) Mediation of spinal nerve injury induced tactile allodynia by descending facilitatory pathways in the dorsolateral funiculus. Neurosci Lett 290:129-132.

Pan ZZ, Williams JT, Osborne PB (1990) Opioid actions on single nucleus raphe magnus neurons from rat and guinea-pig in vitro. J Physiol (Lond) 427:519-532.

Payne R (1986) Neuropathic pain syndromes, with special reference to causalgia and reflex sympathetic dystrophy. Clin J Pain 2:59-73.

Peckys D, Landwehrmeyer GB (1999) Expression of mu, kappa, and delta opioid receptor messenger RNA in the human CNS: a ${ }^{33} \mathrm{P}$ in situ hybridization study. Neuroscience 88:1093-1135.

Pertovaara A (1998) A neuronal correlate of secondary hyperalgesia in the rat spinal dorsal horn is submodality selective and facilitated by supraspinal influence. Exp Neurol 149:193-202.

Pertovaara A, Wei H, Hamalainen MM (1996) Lidocaine in the rostroventromedial medulla and the periaqueductal gray attenuates allodynia in neuropathic rats. Neurosci Lett 218:127-130.

Seltzer Z, Dubner R, Shir Y (1990) A novel behavioral model of neuropathic pain disorders produced in rats by partial sciatic nerve injury. Pain 43:205-218.

Sun H, Ren K, Zhong CM, Ossipov MH, Malan TP, Lai J, Porreca F (2001) Nerve injury-induced tactile allodynia is mediated via ascending spinal dorsal column projections. Pain 90:105-111.

Sung B, Na HS, Kim YI, Yoon YW, Han HC, Nahm SH, Hong SK (1998) Supraspinal involvement in the production of mechanical allodynia by spinal nerve injury in rats. Neurosci Lett 246:117-119.

Tiberi M, Payette P, Mongeau R, Magnan J (1988) [ $\left.{ }^{3} \mathrm{H}\right] \mathrm{U} 69,593$ binding in guinea-pig brain: comparison with $\left[{ }^{3} \mathrm{H}\right]$ ethylketazocine binding at the kappa-opioid sites. Can J Physiol Pharmacol 66:1368-1372.

Wall PD, Gutnick M (1974) Properties of afferent nerve impulses originating from a neuroma. Nature 248:740-743.

Ward SJ, Portoghese PS, Takemori AE (1982) Pharmacological characterization in vivo of the novel opiate, beta-funaltrexamine. J Pharmacol Exp Ther 220:494-498.

Watkins LR, Mayer DJ (1982) Organization of endogenous opiate and nonopiate pain control systems. Science 216:1185-1192.

Wiertelak EP, Maier SF, Watkins LR (1992) Cholecystokinin antianalgesia: safety cues abolish morphine analgesia. Science 256:830-833.

Wu G, Ringkamp M, Hartke TV, Murinson BB, Campbell JN, Griffin JW, Meyer RA (2001) Early onset of spontaneous activity in uninjured $\mathrm{C}$-fiber nociceptors after injury to neighboring nerve fibers. J Neurosci 21:RC140. 